\title{
P129 Arterial Stiffness in Bicuspid or Tricuspid Aortic Valve Aortopathy Using Magnetic Resonance Imaging: Crossing the Physical and Hemodynamic limits?
}

Ariel Pascaner ${ }^{1}$, Sophia Houriez-Gombaud-Saintonge ${ }^{2,3}$, Gilles Soulat ${ }^{4}$, Umit Gencer $^{4}$, Thomas Dietenbeck ${ }^{2}$, Yasmina Chenoune ${ }^{3}$, Nadjia Kachenoura ${ }^{2}$, Elie Mousseaux ${ }^{4}$, Damian Craiem ${ }^{1}$, Emilie Bollache ${ }^{2, *}$

${ }^{1}$ IMETTYB - CONICET - Universidad Favaloro, Buenos Aires

${ }^{2}$ Sorbonne Université, INSERM, CNRS, Laboratoire d'Imagerie Biomédicale, Paris

${ }^{3}$ ESME Sudria Research Lab, Paris

${ }^{4}$ Hôpital Européen Georges-Pompidou, Paris

\begin{abstract}
Purpose: To provide a comprehensive assessment of aortic stiffness, through both local and regional distensibility and pulse wave velocity (PWV), in patients with either a tricuspid (TAV) or bicuspid (BAV) aortic valve and/or aortic dilation using MRI.

Methods: We included 18 patients with TAV and dilated ascending aorta (DTAV, $65 \pm 14$ years, 11 males), 19 patients with a non-stenotic BAV without severe regurgitation ( $55 \pm 15$ years, 17 males), both paired for age, gender and pressures to control groups. All subjects underwent thoracic aortic axial $2 \mathrm{D}+\mathrm{t}$ and sagittal $3 \mathrm{D}+\mathrm{t}$ velocity-encoded $\mathrm{MRI}$ and carotid applanation tonometry. Local ascending (AA) and descending (DA) aortic distensibility as well as aortic arch PWV were automatically measured from 2D+t data [1], while regional AA and DA PWV were calculated from $3 \mathrm{D}+\mathrm{t}$ data [2].

Results: As expected, both DTAV and BAV groups showed significantly increased maximal aortic diameters when compared to their respective control group: $47 \pm 5$ vs $31 \pm 3 \mathrm{~mm}$ and $44 \pm 4$ vs $31 \pm 4 \mathrm{~mm}$, respectively $(p<0.001)$. However, no significant changes were found in local and regional aortic stiffness indices between both patient groups and their matched controls $(p \geq 0.05)$.

Conclusion: 2D or 3D data-derived distensibility or PWV concomitantly and unexpectedly indicate that aortic stiffness was unchanged in patients with aortopathy when compared to matched healthy controls. Since fundamental laminal flow conditions and elastic properties driving Moens-Korteweg models are not reached in highly dilated aortas, the associated turbulent flow, local flow disorganization, changes in derived pressure gradients and flow-wall forces might be more suitable for an early discrimination of patients with valve/aneurismal disease.
\end{abstract}

\section{REFERENCES}

[1] Herment A, Kachenoura N, Lefort M, Bensalah M, Dogui A, Frouin F, et al. Automated segmentation of the aorta from phase contrast MR images: validation against expert tracing in healthy volunteers and in patients with a dilated aorta. J Magn Reson Imaging 2010;31:881-8.

[2] Houriez-Gombaud-Saintonge S, Mousseaux E, Bargiotas I, De Cesare A, Dietenbeck T, Bouaou K, et al. The assessment of aortic pulse wave velocity using 4D flow magnetic resonance imaging: methods comparison. CinC 2017;44:1-4.

(c) 2019 Association for Research into Arterial Structure and Physiology. Publishing services by Atlantis Press International B.V. This is an open access article distributed under the CC BY-NC 4.0 license (http://creativecommons.org/licenses/by-nc/4.0/). 